\title{
Consequências práticas da BNCC e da reforma do ensino médio
}

\section{Introdução}

$\mathrm{E}$ sta avaliação se pauta na análise sistemática dos principais instrumentos que institucionalizaram e visam regulamentar a "reforma do ensino médio", com destaque para a Lei 13.415, que aprovou a antirreforma (impondo mais prejuízos que benefícios à etapa escolar), a Portaria MEC 727/2017, que instituiu o Programa de Fomento às Escolas de Ensino Médio em Tempo Integral (EMTI), e as minutas do Ministério da Educação sobre a Base Nacional Comum Curricular (BNCC) e as Diretrizes Curriculares Nacionais para o Ensino Médio (DCN-EM), ambas enviadas para apreciação e aprovação do Conselho Nacional de Educação (CNE).

Outro eixo da análise consiste em situá-la em âmbito das políticas de ajuste fiscal que abrem caminho para a privatização do ensino médio e que, possivelmente, se estenderá em breve para todo o nível básico, rebaixando o direito constitucional à educação.

O debate público sobre a BNCC não pode prescindir de uma análise sistêmica sobre as políticas para o ensino médio, uma vez que a estratégia global da antirreforma é impor dicotomia formativa, reducionismo curricular, priorização de competências e rebaixamento de direitos que vão muito além da BNCC. E a estratégia de mercantilização do ensino médio (e da educação básica) é o principal mote da reforma, seguindo orientação do brutal ajuste fiscal imposto pela Emenda Constitucional (EC) 95 e outros expediente do governo golpista de Michel Temer, que situam a educação básica pública brasileira no espectro das políticas ultraliberais que dominam o país no pós-Golpe de 2016.

Neste sentido, a análise sistemática sobre as alterações impostas pelo governo ilegítimo à organização do ensino médio ${ }^{1}$ cumpre o objetivo de informar a categoria dos trabalhadores em educação, os estudantes, as comunidades escolares e as entidades e instituições que defendem a escola pública, acerca de aspectos que compreendem a reformulação da última etapa da educação básica, a fim de apontar as limitações, contradições e retrocessos inerentes a essa política. E, de posse das fundamentações, é imprescindível que as entidades educacionais organizem a mobilização social para contrapor a implementação da antirreforma em todo o País. 


\section{Formalidade e insegurança jurídica na antirreforma do ensino médio}

Toda política pública é elaborada com intencionalidades, tendo objetivos, públicos alvos e mecanismos de financiamento, implementação e fiscalização. Sua elaboração deve primar pelo debate público, sobretudo quando os objetivos focarem verdadeiramente a sociedade e não os agentes privados. Portanto, os parâmetros de elaboração das políticas públicas são fundamentais para se verificar a quem de fato elas atendem e o que pretendem mediar/intervir nas relações sociais.

Todos sabemos que o debate da antirreforma do ensino médio desprezou a opinião de estudantes, trabalhadores em educação e especialistas do tema. A edição de Medida Provisória (MP) para tratar de assunto de tamanha envergadura e repercussão social, seguida da dissolução do Fórum Nacional de Educação (FNE) - composto democraticamente por entidades da sociedade que deveriam opinar sobre a BNCC - foram ações calculadas do governo ilegítimo para cercear o debate público, facilitando a aprovação de suas (des)medidas.

Não obstante as flagrantes ações antidemocráticas, pode-se dizer que, até o momento, a antirreforma educacional está acobertada pelo manto da legalidade formal. A Lei 13.415 foi aprovada no Congresso Nacional para alterar a LDB; o Parlamento aprovou empréstimo junto ao Banco Internacional para Reconstrução e Desenvolvimento (Bid) para financiar a reforma educacional em algumas escolas de referência nos estados; o Ministério da Educação publicou a portaria 727/17 para instituir regime de colaboração de custeio nas escolas de referência utilizando recursos do empréstimo contraído no Bird; o mesmo MEC, com base na Constituição Federal - CF (art. 210), na Lei de Diretrizes e Bases da Educação Nacional - LDB (art. 26) e no Plano Nacional de Educação - PNE (estratégias 2.1 e 3.2), enviou minutas da BNCC e de alteração das DCN-EM ao Conselho Nacional de Educação, e este órgão apenso ao MEC convocou cinco audiências públicas para debater parte dessas minutas (somente a BNCC!).

Tal como acontece em outras áreas, o formalismo jurídico-institucional tem chancelado medidas que desprezam não só a essência material de fatos, atos e normas jurídicas, especialmente suas repercussões concretas na sociedade (ex: reforma trabalhista, ajuste fiscal (EC 95), reforma do ensino médio, renegociação da dívida pública entre estados e União, entre outras), como também a ausência de amplo debate público sobre temas sensíveis à sociedade e à preservação e aprimoramento do Estado Democrático de Direito.

Mesmo diante do aparato formal supracitado, a antirreforma do ensino médio ainda precisa superar uma pendência jurídica. É que o STF permitiu que a MP 746, aprovada sob rito sumário pelo Congresso e convertida na Lei 13.415, tramitasse, sem que duas ações diretas de inconstitucionalidade (ADI), uma delas da CNTE, fossem julgadas em tempo hábil. As ações questionam os requisitos de relevância e urgência da Medida Provisória, no caso concreto da reforma educacional, além de questões de mérito. 
Diga-se de passagem, bem que o relator das ADI no STF, ministro Edson Fachin, tentou colocar pá de cal na situação, arquivando as ações sob o argumento de "perda de objeto" após a aprovação da Lei 13.415. Mas sua decisão monocrática foi revista em sede de recurso de agravo, uma vez que há jurisprudência no Tribunal admitindo a inconstitucionalidade de leis oriundas de medidas provisórias com vícios formais, mesmo após aprovação no Congresso (caso idêntico à MP 746!).

O processo que poderá declarar a inconstitucionalidade da Lei 13.415 aguarda pauta no plenário do STF desde agosto de 2017. E os efeitos da decisão pendente poderão atingir todas as normativas e atos subsequentes à Lei 13.415 (Portarias, BNCC, DCN). Ou seja: ainda paira insegurança jurídica sobre a antirreforma do ensino médio, a qual, tudo indica, somente deverá ser dirimida após as eleições presidenciais de 2018, em razão do elevado conteúdo político que envolve o assunto (trata-se de uma reforma restritiva de direitos, diametralmente oposta à vontade popular sufragada em 2014 e que poderá ser reiterada no pleito eleitoral de 2018).

\section{O conteúdo da BNCC e sua relação com os demais instrumentos da antirre- forma do ensino médio}

A CNTE já se manifestou em diversos fóruns sobre a proposta da BNCC, queé apenas um instrumento para operacionalizar a Reforma do Ensino Médio, aprovada por um governo sem legitimidade e que negou a oportunidade de debate público ao encaminhar a Reforma ao Congresso na forma de Medida Provisória (MP 746/2016).

A Lei 13.415, sobre a qual a BNCC do Ensino Médio atuará, impõe enormes retrocessos aos/as educadores/as e à sociedade brasileira. De um lado, fomenta a privatização da educação básica, repassando para o setor privado os currículos flexíveis, especialmente da educação técnica-profissional, que deverá ser a mais explorada pelos sistemas e redes de ensino. De outro, cria um verdadeiro apartheid socioeducacional, instituindo escolas para ricos e classe média alta - com currículos "a la carte" onde empresários poderão cobrar por disciplinas que estão fora das 1.800 horas obrigatórias da BNCC -, e escolas para pobres e classe média baixa, estas com currículos limitados às 1.800 horas e com apenas duas disciplinas obrigatórias (português e matemática).

Neste sentido, as modificações pontuais na proposta da BNCC, ventiladas pelo MEC, não serão suficientes para alterar as concepções estruturais e político-pedagógicas impostas pela Lei 13.415, que deve ser revogada!

É preciso ficar claro que a Reforma do Ensino Médio e seu instrumento de operacionalização (a BNCC) fazem parte do projeto maior de um governo sem legitimidade eleitoral e que é produto do Golpe. A mercantilização e a privatização do ensino médio, fomentadas pela Reforma, caminham em sintonia com a Emenda Constitucional n. 95, a qual congela por 20 anos os investimentos públicos em políticas sociais, inclusive na educação. 
E para economizar dinheiro, o Poder Público ofertará menos conteúdos obrigatórios aos estudantes e, consequentemente, contratará menos professores para lecionar. E os/as educadores/as que ainda permanecerem nas redes de ensino poderão ter suas relações de trabalho precarizadas pela Reforma Trabalhista (Lei 13.467).

Por isso, não adianta remendar algo que pretende destruir a educação pública e eliminar postos de trabalho dos trabalhadores em educação (professores e funcionários administrativos escolares).

A antirreforma educacional, na qual se apoia a BNCC, atende a um modelo excludente e limitado de oferta escolar voltado para a privatização e terceirização do ensino médio, através de parcerias público-privadas (PPP), onde o Estado se desresponsabiliza em ofertar a maior parte do currículo escolar. Com isso, o direito constitucional à educação básica é rebaixado drástica e perigosamente, atendendo a interesses exclusivos do mercado.

Mesmo tendo previsão na LDB e no PNE, quem realmente estabeleceu os limites de abrangência da BNCC do ensino médio foi a Lei 13.415. E ainda há expectativa de que as DCN-EM delimitem mais ainda o alcance e a forma de aplicação da base curricular comum, impondo prejuízos extras aos estudantes e educadores.

A parte introdutória da BNCC tenta legitimar seu conteúdo fazendo menção a inúmeros conceitos de igualdade, diversidade, equidade, bem como ao pacto federativo e ao regime de colaboração. Porém, na prática, sua aplicação está condicionada a 1.800 horas de uma etapa escolar prevista para alcançar 4.200 horas em 2022. Ou seja: a formação comum dos estudantes do ensino médio, após a implementação integral da Lei 13.415, corresponderá a menos da metade da carga horária geral.

Embora a base curricular comum do ensino médio privilegie a autonomia escolar, remetendo a construção dos currículos aos profissionais e comunidades, à luz do projeto político-pedagógico de cada escola, preocupa o nível de defasagem que os estudantes terão em decorrência da limitação do tempo para ministrar conteúdos das áreas "não obrigatórias" ao longo de toda a etapa escolar. E uma forma de amenizar esse problema estaria na implementação da oferta integrada de conteúdos comuns e flexíveis, ao longo de todo o ensino médio, priorizando todas as áreas de conhecimentos específicos pelas escolas.

Conforme será visto mais adiante, a minuta que propõe alterar as diretrizes curriculares nacionais para o ensino médio dispõe em sua art. $7^{\circ}$ a possibilidade de oferta integrada da BNCC com os itinerários formativos - e a própria BNCC aponta a possibilidade de ambos os conteúdos (comuns e flexíveis) serem ministrados ao longo dos três anos -, razão pela qual a luta escolar deverá caminhar nesta direção.

Caso a orientação acima não prevaleça, então, invariavelmente, a BNCC se voltará exclusivamente para os testes nacionais e internacionais padronizados e para a privatização da escola pública, na medida em que os sistemas de ensino poderão priorizar apenas 
as disciplinas de Língua Portuguesa e Matemática (em contradição com o propalado discurso das áreas de conhecimento!), disponibilizando a parte flexível do currículo para a rede particular (especialmente através de cursos técnicos e de aprendizagem profissional). Neste formato claramente pretendido pelos formuladores da antirreforma do ensino médio, as áreas de Ciências da Natureza e suas Tecnologias e de Ciências Humanas e Sociais Aplicadas formarão um "cardápio a la carte" alternativo de conteúdos que poderão ser oferecidos aos estudantes em algum período da etapa escolar, ou mesmo durante os três anos, porém dentro do limite de 1.800 horas que já comporta as duas "disciplinas" obrigatórias - reduzindo assim a incidência desses conteúdos na formação estudantil.

Ainda sobre as prioridades curriculares, a BNCC e toda a antirreforma do ensino médio não conseguiram adaptar a fragmentação de conteúdos imposta pela Lei 13.415 aos dispositivos do art. 26, caput e $\S 1^{0}$ da LDB, os quais fixam uma base comum ampla e sólida para a formação dos estudantes nas etapas do ensino fundamental e médio, nos seguintes termos:

Art. 26 Os currículos da educação infantil, do ensino fundamental e do ensino médio devem ter base nacional comum, a ser complementada, em cada sistema de ensino e em cada estabelecimento escolar, por uma parte diversificada, exigida pelas características regionais e locais da sociedade, da cultura, da economia e dos educandos.

$\S 1^{\circ}$ Os currículos a que se refere o caput devem abranger, obrigatoriamente, o estudo da língua portuguesa e da matemática, o conhecimento do mundo físico e natural e da realidade social e política, especialmente do Brasil.

A bem da verdade, a BNCC aborda todas as áreas de conhecimento previstas no supracitado artigo da LDB, porém a Lei 13.415 delimita a aplicação dos conteúdos da base comum a 1.800 horas e sua obrigatoriedade nos três anos regulares APENAS às disciplinas de Português e Matemática! A alternativa para superar em parte essa contradição legal está sendo apontada na regulamentação da BNCC e das DCN-EM, possibilitando a oferta integrada das áreas comuns e flexíveis, porém mantendo a limitação de 1.800 horas para a BNCC.

Outro dispositivo legal obedecido pela BNCC do ensino médio, embora com as mesmas limitações de "obrigatoriedade" impostas a outras áreas de conhecimento, diz respeito ao art. 26-A da LDB, in verbis:

Art. 26-A. Nos estabelecimentos de ensino fundamental e de ensino médio, públicos e privados, torna-se obrigatório o estudo da história e cultura afro-brasileira e indígena.

$\S 11^{\circ}$ O conteúdo programático a que se refere este artigo incluirá diversos aspectos da história e da cultura que caracterizam a formação da população brasileira, a partir desses dois grupos étnicos, tais como o estudo da história da África e dos africanos, a luta dos negros e dos povos indígenas no Brasil, a cultura negra e indígena brasileira e o negro e o indio na formação da sociedade nacional, resgatando as suas contribuições nas áreas social, econômica e política, pertinentes à história do Brasil. 
$\S 2^{\circ}$ Os conteúdos referentes à história e cultura afro-brasileira e dos povos indígenas brasileiros serão ministrados no âmbito de todo o currículo escolar, em especial nas áreas de educação artística e de literatura e história brasileiras.

É importante anotar com cuidado esses comandos legais da LDB (art. 26 e 26-A), pois a antirreforma do ensino médio não apenas permite flexibilizá-los dentro de uma lógica economicista, privatista e mercadológica, como sugere interpretação condicionada de ambos ao que foi posteriormente aprovado pela Lei 13.415. E, em se mantendo a lógica da hierarquia da reforma do ensino médio diante dos demais artigos da LDB (como de fato está ocorrendo!), as áreas de conhecimento ditas de aplicação obrigatória pelo $§ 1^{\circ}$ do art. 26 da LDB, embora estejam contempladas na BNCC, sofrerão restrição de conteúdos a serem ministrados aos estudantes em função do tempo escasso (1.800 horas).

A minuta de reformulação das DCN-EM, não disponibilizada pelo Conselho Nacional de Educação para debate conjunto com a BNCC, tenta remediar algumas incongruências da Lei 13.415, ao mesmo tempo em que promove outras mais grotescas. Como dito acima, o documento oficioso dispõe que os conteúdos da BNCC poderão ser desenvolvidos de forma integrada com os conteúdos flexíveis, durante toda a etapa do ensino médio, contudo observando-se a trava de 1.800 horas. Por outro lado, indica a possibilidade de flexibilizar $40 \%$ do currículo "regular" e "integral" na forma a distância, podendo a educação de jovens e adultos (EJA) ser disponibilizada 100\% fora da escola.

Sobre a parte flexível do currículo - que induz equivocadamente a oferta dicotômica do currículo, especialmente na área da Formação Técnica e Profissional -, o documento da BNCC contém indicativos de competências e habilidades para os currículos dos diferentes itinerários formativos, com exceção da formação técnica. A oferta desse último itinerário formativo ébastante explorada na Lei 13.415 e na minuta de DCN-EM, especialmente com a perspectiva de estabelecer parcerias público-privadas, que serão apontadas adiante.

Antes de adentrar às especificidades de cada normativa que integra a antirreforma educacional, reiteramos que o formato pedagógico do "novo" ensino médio - sobretudo sua orientação para a formação técnica de baixa qualidade (cursos de qualificação profissional, tipo eletricista, estética corporal, entre outros) - caminha na direção de um verdadeiro apartheid educacional, pois claro está que se pretende estabelecer diferentes tipos de escolas para diferentes públicos, com perspectivas distintas de futuro (leia-se: oportunidades desiguais para as classes sociais).

Infelizmente, a antirreforma caminha na direção oposta das recentes políticas de inclusão escolar e universitária, pois aponta para a maior parte da população (classes populares que acessam a escola pública) o ensino médio como etapa de conclusão dos estudos - independente da vontade dos estudantes.

O déficit de conteúdos a que milhares de estudantes estarão submetidos, seja pela limitação de aplicação da BNCC, seja pela não obrigatoriedade de oferta de todos os 
itinerários formativos na rede pública (em razões das contingências financeiras), ou ainda em função da flexibilização curricular que admite computar atividades a distância e carga horária de cursos técnicos diversos e de trabalho voluntário ao currículo do ensino médio regular, tende a inviabilizar o acesso às escolas públicas ou o ingresso às universidades públicas.

A fim de melhor compreender a estrutura e a aplicação da antirreforma do ensino médio (BNCC, Lei 13.415, Portaria 727 e minuta de DCN-EM), passemos à análise dos seguintes pontos, além de outros produzidos anteriormente pela CNTE:

a. Estrutura Curricular - em primeiro lugar, a reintrodução da dicotomia curricular no ensino médio (parte comum e parte flexível), ressuscitando o antigo Decreto 2.208/97, agora em forma de Lei 13.415, interfere sobremaneira na oferta regular de ensino com qualidade (pois admite todo tipo de convênio privado para formação profissional fora da escola) e avança em novas contradições como as que envolvem os artigos $26, \S 1^{\circ}$ e $35-\mathrm{A}, \S 3^{\circ}$ da LDB, referentes à aplicação efetiva de conteúdos "obrigatórios" da base comum. Trata-se de assunto que desmonta o discurso da formação integral pretendida pela Lei 13.415 e a BNCC e que já havia sido superado, em 2004, com a publicação do Decreto 5.154, posteriormente regulamentado pela Resolução CNE/CEB no 02/12, que diz em seu art. 8으, § 20: "A organização por áreas de conhecimento não dilui nem exclui componentes curriculares com especificidades e saberes próprios construídos e sistematizados, mas implica no fortalecimento das relações entre eles e a sua contextualização para apreensão e intervenção na realidade, requerendo planejamento e execução conjugados e cooperativos dos seus professores".

b. Disposição dos conteúdos na BNCC - para cada uma das quatros áreas de conhecimento comuns a BNCC dispõe de indicações de "competências" e "habilidades" que deverão integrar os currículos escolares. Estes, por sua vez, mantêm relativo nível de autonomia na medida em que deverão ser elaborados à luz do projeto pedagógico da escola, "considerando as características de sua região, as culturas locais, as necessidades de formação e as demandas e aspirações dos estudantes" (BNCC, p. 471). A área de Linguagens inclui Língua Portuguesa, Arte, Educação Física e Língua Inglesa, com preponderância para o estudo obrigatório de Português (nos três anos). As demais áreas, com exceção da Matemática (também obrigatória em toda a etapa escolar) abrangem os conhecimentos das disciplinas tradicionais (História, Geografia, Sociologia, Filosofia, Biologia, Física e Química), porém disputarão a carga horária de 1.800 horas destinada a todos os conteúdos comuns, inclusive àqueles "obrigatórios" nos três anos (Português e Matemática).

c. Distribuição da BNCC na carga horária do ensino médio - o parágrafo $5^{\circ}$ do art. 35-A da LDB, introduzido pela Lei 13.415, limita o cumprimento de toda a BNCC em no máximo 1.800 horas. Já o $\S 1^{\circ}$ do art. 24, também da LDB e com redação conferida pela Lei do Ensino Médio, estabeleceu 2.400 horas de carga horária para o ensino médio até $1^{\circ}$ de março de 2017, ampliando essa carga curricular entre 2017 e 2022 para pelo menos 3.000 horas. A partir desta data, o ensino médio passará ter duração de 4.200 horas. Diante destes parâmetros, observa-se que o tempo disponível para a formação comum dos estudantes será reduzido de $75 \%$ até 2017 , para $60 \%$ entre 2017 e 2022 e, finalmente, para $42,8 \%$ a partir do último ano de implantação da reforma (2022). Para agravar ainda mais essa tendência de menos formação comum obrigatória, a minuta de resolução que visa alterar as DCN-EM prevê a possibilidade de cumprimento de até $40 \%$ de todo o currículo escolar regular do 
ensino médio (inclusive a parte da BNCC) na forma a distância e 100\% para a modalidade de EJA - mais um disparate para atender interesses comerciais!

d. Itinerários formativos sob a ótica curricular - a BNCC orienta também conteúdos gerais, específicos e habilidades para a construção dos currículos da parte flexível, com exceção da Educação Técnica e Profissional. Essa parte do currículo, oferecida separadamente da BNCC (dicotomia) e com carga horária que se tornará majoritária a partir de 2022, tem sua regulação expressa na Lei 13.415 (art. 36 da LDB) e na minuta de resolução das DCN-EM, de posse do CNE. A Lei e a minuta de DCN-EM contêm vários problemas para a formação escolar de qualidade, com destaque para as seguintes questões:

- Não obrigam os entes públicos a ofertarem todas as áreas específicas de conhecimento, restringindo o direito de escolha dos estudantes por áreas do currículo flexível, consequentemente, submetendo os discentes à oferta privada (verdadeira mitigação do direito público e subjetivo à educação!).

- Priorizam a oferta sequencial ou concomitante dos itinerários formativos (art. 14, § único, inciso II da minuta de DCN-EM), a fim de priorizar os convênios com a iniciativa privada, em desarmonia com o art. $7^{\circ}, 3^{\circ}$ da mesma normativa, que admite a oferta integrada da BNCC com a parte flexível do currículo. E é nesse quesito que a luta social em defesa da qualidade do ensino médio deverá se ater, cobrando dos gestores públicos a implementação dos itinerários formativos que as comunidades escolares julgarem necessários nas redes públicas de educação do país de forma integrada com a BNCC.

- Prejudicam a formação integral dos estudantes, limitando o acesso aos conteúdos indispensáveis à formação cidadã e para o ingresso na universidade.

- Consideram o trabalho voluntário, os cursos de aprendizagem profissional e/ou quaisquer cursos técnicos reconhecidos pelo setor produtivo através da Classificação Brasileira de Ocupações (CBO) como parte do currículo escolar.

- A minuta de DCN-EM disponibiliza 40\% do currículo regular (comum e flexível) para atividades a distância, sendo 100\% da EJA de forma discricionária do Poder Público.

- Permite a oferta de conteúdos nos formatos de séries anuais, ciclos, módulos, sistema de crédito e outros, estimulando ainda mais a desvinculação dos estudantes da escola, já que poderão optar por módulos (tipo cursos do Pronatec) para preencher seus currículos flexíveis através da área da Formação Técnica e Profissional. 
e. Itinerário formativo sob a ótica das parcerias público privadas - toda a antirreforma educacional é construída com a lógica de repassar a oferta majoritária do currículo do ensino médio para a iniciativa privada. E o formato de organização curricular da parte flexível expõe sem constrangimentos a premissa privatista, mercantilista e terceirizada da antirreforma, a ponto de considerar para a composição do currículo escolar quaisquer diplomas de cursos técnicos ou de aprendizagem privados (ex: Sistema S), previstos na Classificação Brasileira de Ocupações (CBO) e no Catálogo Nacional de Cursos Técnicos (inclusive os experimentais que possam ser incluídos no Catálogo no prazo de três anos). Dessa forma, os cursos de qualificação profissional (ex: Pronatec) passam a fazer parte do currículo do ensino médio (na forma de itinerários formativos), reforçando a tese de terminalidade dos estudos para muitos jovens nesta etapa escolar. Aliás, os estados poderão oferecer ou estabelecer convênios remunerados com o setor privado para dispor de mais de um itinerário formativo aos estudantes egressos do ensino médio. Com isso, o Estado brasileiro (comandado por quem promoveu o Golpe em 2016) espera "desafogar" a demanda por ensino superior sob a lógica do ajuste fiscal e atender as necessidades de mão de obra barata do setor produtivo.

f. Portaria MEC 727/17 promove a seletividade em escolas de referência, rebaixamento na qualidade da educação e exclusão educacional - entre as análises anteriores da CNTE, consta uma que trata dos efeitos da antirreforma do ensino médio no sentido de criar escolas de referência, nos estados, promovendo a exclusão educacional tanto no ensino médio como na etapa fundamental ${ }^{2}$. Isso porque a Portaria 727, que estabelece "novas diretrizes, novos parâmetros e critérios para o Programa de Fomento às Escolas de Ensino Médio em Tempo Integral - EMTI", condiciona os convênios financeiros a exigências que não dialogam com a realidade do País. Para ficar num único exemplo, mais da metade dos municípios brasileiros possui apenas 1 (UMA) escola de ensino médio, na qual, geralmente, também são atendidos estudantes do ensino fundamental e da EJA. Porém, para que essa única escola receba recursos federais do EMTI, ela terá que atender exclusivamente o ensino médio na forma regular, dispensando os demais estudantes. E mais: essa instituição escolar dificilmente disporá de mais de um itinerário formativo para seus estudantes, comprometendo o acesso da maioria dos discentes às áreas de preferência do currículo flexível.

g. Efeitos colaterais da antirreforma (municipalização do ensino fundamental, terceirização, demissão e rebaixamento profissional dos professores das disciplinas comuns "não obrigatórias" nos três anos regulares, estímulo à desprofissinalização) - além da municipalização que está em pleno processo de implementação País afora - sobrecarregando as finanças municipais com matrículas do ensino fundamental até então financiadas pelo ente estadual -, a antirreforma investe contra a categoria do magistério, priorizando a contratação de profissionais de apenas duas áreas (Português e Matemática). Essa foi a alternativa encontrada pelo Estado para suprir os déficits de professores nas áreas de Química, Física, Biologia, Artes, entre outras. Ou seja: a escola disponibiliza menos conteúdos aos estudantes e consequentemente contrata-se menos profissionais (visão economicista e descompromissada com o direito à educação). Além de contratar menos profissionais, o Poder Público poderá autorizar suas redes de ensino e a rede privada (sobretudo essa!) a dispor de profissionais com Notório Saber para ministrar aulas em cursos de Formação Técnica e Profissional. Assim, abre-se a possibilidade de se contratar ainda menos profissionais de áreas do conhecimento escolar "não obrigatórias", bastando o Estado ofertar ou firmar contratos de itinerário formativo na área da Formação Técnica e Profissional. Eis a fórmula para aprofundar a precarização da profissão do magistério e, de quebra, intervir no processo de organização sindical desta categoria considerada vanguarda nas lutas sociais em todo país. 


\section{Consequências práticas da bncc e da reforma do ensino médio para as esco- las de todo o País}

O alerta da CNTE para que não se faça análises da BNCC desconsiderando o contexto maior da Reforma do Ensino Médio, se apoia nas seguintes consequências:

» A antirreforma obrigará as redes públicas de educação dos estados e do DF, principais responsáveis pelo ensino médio, a ofertarem obrigatoriamente apenas duas disciplinas nos três anos de currículo escolar (Português e Matemática).

» As demais disciplinas, que poderão eventualmente integrar as 1.800 horas de oferta da BNCC com carga horária bastante reduzida, não possuem obrigatoriedade de oferta. São elas: História, Geografia, Sociologia, Filosofia, Artes, Educação Física, Língua Estrangeira, Física, Química, Biologia.

» As escolas poderão oferecer a BNCC de forma integrada ou concomitante com os currículos flexíveis. Porém, nenhuma escola será obrigada a oferecer mais de um currículo flexível, a saber: i. Linguagens e suas tecnologias; ii. Matemática e suas tecnologias; iii. Ciências da natureza e suas tecnologias; iv. Ciências humanas e sociais aplicadas; v. Formação técnica e profissional.

» Cerca de 3 mil municípios no Brasil possuem apenas uma escola de ensino médio e nesses locais os estudantes não terão como optar pela área flexível de sua preferência.

» As escolas passarão a certificar a conclusão do ensino médio de duas formas: a parte da BNCC, cuja obrigatoriedade é Português e Matemática, e a parte flexível, a qual poderá conter os seguintes registros no histórico escolar: i) cursos de aprendizagem oferecidos por centros ou programas ocupacionais (ex: Pronatec); ii) cursos técnico-profissionais do Catálogo do MEC; iii) demonstrações práticas; iv) experiência de trabalho supervisionado ou outra experiência adquirida fora do ambiente escolar (ex: trabalho voluntário); v) estudos realizados em instituições de ensino nacionais ou estrangeiras; vi) cursos realizados por meio de educação a distância ou educação presencial mediada por tecnologias.

»Com o novo formato do ensino médio o estudante frequentará a escola da seguinte forma:

- Até 2022, quando os currículos deverão ter no mínimo 3.000 horas (e a maioriajá é assim): 1.800 horas de BNCC sob a supervisão dos professores e 1.200 horas opcionalmente fora da escola, por meio de atividades listadas no tópico anterior e certificadas por instituições extraescolares. 
- Após 2022, quando os currículos deverão ter 4.200 horas divididas em 1.800 horas de BNCC e 2.400 horas de parte flexível: 1.800 horas sob a supervisão direta da escola e 2.400 horas opcionalmente fora da escola, por meio de certificações diversas que integrarão o histórico escolar.

- Educação a distância: a minuta de alteração das Diretrizes Curriculares Nacionais para o ensino médio enviada pelo MEC ao Conselho Nacional de Educação (documento não público!) prevê a oferta de $40 \%$ do total da carga horária do ensino médio (inclusive a parte da BNCC) na forma a distância.

Em suma: a proposta "revolucionária" do novo ensino médio convida os estudantes a não frequentarem a escola, impõe reducionismo curricular e ainda por cima pretende cortar absurdamente o número de professores nas escolas, inclusive de Português e Matemática, uma vez que quase a metade do conteúdo dessas disciplinas poderá ser oferecido a distância.

» A BNCC faz fundamentação teórica apenas das áreas de Linguagens e Matemática, em claro desprezo às demais áreas do conhecimento que o MEC e a Lei 13.415 julgam "não obrigatórias". No entanto, mesmo na área de Linguagens os/ as professores/as precisam saber que a obrigatoriedade será apenas Português, podendo ficar de fora das distribuições de aulas as disciplinas de Artes, Língua Estrangeira e Educação Física, as quais poderão ser ministradas na parte flexível do currículo. Porém não há garantias de que a escola ofertará esta e outras áreas do currículo flexível.

O MEC ajudará a financiar por quatro anos algumas escolas de referência de ensino médio nos estados, atingindo menos de 7\% das matrículas, e a grande massa dos estudantes e das escolas ficará à mercê dos parcos recursos públicos e das parcerias com o setor privado para ofertar o currículo flexível.

» Ao invés de investir na infraestrutura escolar, no tempo integral, na formação e valorização dos profissionais, o MEC opta por destruir o ensino médio, limitando a aprendizagem estudantil aos conteúdos cobrados em testes nacionais e internacionais de proficiência estudantil. Por tabela, os estudantes da escola pública ficarão cada vez mais distantes da universidade, pois, além de limitar a obrigatoriedade das disciplinas, não há nenhuma garantia de que os conteúdos que formam o documento da BNCC serão ministrados em algum momento do ensino médio. 


\section{Indicativos para a luta social}

Diante da complexidade e gravidade das propostas contidas na ampla e profunda reforma do ensino médio, a qual se pauta num projeto excludente e subserviente de sociedade, impondo à juventude das classes populares menos oportunidades educacionais em benefício dos setores produtivos que pautarão os currículos escolares, a CNTE reitera as seguintes frentes de luta para combater os retrocessos da reforma educacional:

1. Acompanhamento e intervenção nos processos judiciais em trâmite do STF, que requerem a declaração de inconstitucionalidade da MP 746 e por consequência da Lei 13.415.

2. Debate permanente com a comunidade escolar e com os gestores públicos para se evitar restrições do acesso à escola pública e aos conteúdos comuns (obrigatórios) da educação básica (art. 26, § $1^{0}$ da LDB).

3. Exigência de implementação de todos os itinerários formativos considerados imprescindíveis pela comunidade escolar, com a garantia de contratação de profissionais efetivos e com formação e valorização assegurados em planos de carreira da categoria.

4. Exigência de oferta articulada e integrada da BNCC com os diferentes itinerários formativos, em todas as escolas públicas, como forma de amenizar (ou até superar) o retrocesso da dicotomia curricular e o enxugamento dos conteúdos básicos e indispensáveis à formação humanística e cidadã dos estudantes, bem como para promover as condições de acesso de todos/as que pretenderem ingressar na universidade.

5. Garantia de recursos financeiros e pedagógicos para a construção democrática dos currículos da BNCC e da parte flexível, através dos projetos político-pedagógicos das escolas.

6. Mobilizar a comunidade escolar e as instituiç̧ões públicas para não permitir a disponibilização da carga horária do ensino médio regular na forma a distância.

7. Efetivar o mapeamento das matrículas escolares para evitar possíveis evasões escolares em decorrência dos convênios em âmbito do Programa de Fomento às Escolas de Ensino Médio em Tempo Integral (EMTI - Portaria MEC 727/17), que prioriza a instituição de escolas de referência.

8. Impedir processos obscuros e apressados de municipalização das matrículas do ensino fundamental, conscientizando as gestões municipais sobre os riscos de tais compromissos assumidos sem a devida contrapartida financeira. 
9. Atuar em todas as frentes institucionais e sociais para impedir a privatização do ensino médio (especialmente do currículo flexível) e a terceirização dos/as educadores/ as através de parcerias público privadas ou qualquer outra modalidade de repasse público para a rede particular. Esse mecanismo, além de minar a capacidade de investimento público na escola pública, compromete a qualidade da formação básica por meio de currículos rebaixados e desatrelados com os fundamentos epistemológicos da formação de nível básico.

Diante desses e de outros compromissos indispensáveis para impedir os retrocessos impostos pela antirreforma do ensino médio, a CNTE reforça o convite a seus sindicatos filiados e a toda comunidade educacional do País para que promovam debates, seminários, assembleias e demais atividades em conjunto com a comunidade escolar e com outros atores sociais e institucionais (Ministério Público, Tribunais de Contas, Poder Judiciário), a fim de envolver a sociedade nesta importante tarefa de intervir no processo de não implementação das (des)medidas desta reforma nefasta.

A restrição de direitos, a privatização da educação pública e a segregação social dispostos nos objetivos ocultos da antirreforma precisam ser disseminados para que a narrativa correta sobre a reforma do ensino médio seja estabelecida na sociedade e para que mais uma tentativa de crime de lesa pátria promovida pelos agentes do golpe institucional seja interrompida.

\section{Notas}

1 Documentos disponíveis em:

Lei 13.415/2017, que alterou a LDB (Lei de Diretrizes e Bases da Educação) para instituir ampla reforma na etapa do ensino médio: http://www.planalto.gov.br/ccivil_03/_ato2015-2018/2017/lei/113415.htm

Portaria MEC 727/2017, que estabelece diretrizes, parâmetros e critérios para o Programa de Fomento às Escolas de Ensino Médio em Tempo Integral - EMTI, revogando a Portaria MEC 1.145/2016: http://www. fnde.gov.br/acesso-a-informacao/institucional/legislacao/item/10931-portaria-mec-n\%C2\%BA-727,-de-13-de-maio-de-2017

Minuta de Resolução ___ _2018, em debate no Conselho Nacional de Educação - CNE, a qual pretende revogar a Resolução CNE/CEB 02/2012, a fim de "atualizar" as Diretrizes Curriculares Nacionais para o Ensino Médio aos dispositivos da Lei 13.415. Indisponível para consulta pública.

Base Nacional Comum Curricular do Ensino Médio (minuta para debate no CNE): http://portal.mec.gov. br/index.php?option=com_docman\&view=download\&alias=85121-bncc-ensino-medio\&category_slug=abril-2018-pdf\&Itemid=30192

2 Disponível em: https://www.cnte.org.br/images/stories/cadernos_educacao/cadernos_educacao_30.pdf, pág. 33. 